\title{
Testimonio sobre el abuso sexual y su efecto jurídico en las sentencias emitidas por tribunales
}

\author{
Testimony on sexual abuse and its legal effect on sentences issued by courts \\ Testemunho sobre abuso sexual e seu efeito legal sobre as sentenças judiciais
}

RESUMEN $\mid$ La investigación tuvo como objetivo general analizar el efecto jurídico que provoca el testimonio de los niños y adolescentes víctimas del delito de abuso sexual, en las sentencias emitidas en el tribunal de Garantías Penales de Ecuador. Su metodología fue de tipo descriptiva- causal, con un diseño no experimental, el método fue inductivo. La técnica e instrumentos estuvo conformado por el fichaje y la encuesta (fichaje y cuestionario), la población y muestra fue representada por (6) Jueces del Tribunal de Garantías Penales con sede en el cantón de Riobamba, (4) Fiscales y (4) Abogados en libre ejercicio de la profesión. El resultado obtenido fue que efectivamente el testimonio de los niños y adolescentes víctimas del delito de abuso sexual causa efecto en las sentencias emitidas por la unidad Judicial por lo que es necesario optar por otros medios de pruebas.

Palabras clave: Abuso sexual; delito; testimonios de los menores; tipo de abuso sexual, sujeto activo

ABSTRACT

RESUMO
The general objective of the investigation was to analyze the legal effect caused by the testimony of children and adolescents who are victims of the crime of sexual abuse, in the sentences issued in the Court of Criminal Guarantees of Ecuador. Its methodology was descriptive-causal, with a non-experimental design, the method was inductive. The technique and instruments consisted of the registration and the survey (registration and questionnaire), the population and sample were represented by (6) Judges of the Criminal Guarantees Court based in the canton of Riobamba, (4) Prosecutors and (4) Lawyers in free exercise of the profession. The result obtained was that effectively the testimony of children and adolescents' victims of the crime of sexual abuse has an effect on the sentences issued by the Judicial unit, which is why it is necessary to opt for other means of evidence.

Palabras clave: Sexual abuse; crime; testimony of minors; type of sexual abuse, active subject

O objetivo geral da investigação foi analisar o efeito jurídico causado pelo testemunho de crianças e adolescentes vítimas do crime de abuso sexual, nas sentenças proferidas no Tribunal de Garantias Penais do Equador. Sua metodologia foi descritiva-causal, com desenho não experimental, o método foi indutivo. A técnica e os instrumentos consistiram no registo e no inquérito (registo e questionário), a população e a amostra foram representadas por (6) Juízes do Tribunal de Garantias Criminais sedeados no cantão de Riobamba, (4) Procuradores e (4) Advogados em livre exercício da profissão. $O$ resultado obtido foi que efetivamente o depoimento de crianças e adolescentes vítimas de crime de abuso sexual incide nas sentenças proferidas pela Unidade Judiciária, sendo necessário optar por outros meios de prova.

Palavras-clave: Abuso sexual; crime; testemunho de menores; tipo de abuso sexual, perpetrador 


\section{INTRODUCCIÓN}

El abuso sexual al que son víctimas los niños, niñas y adolescentes, conlleva a muchos conflictos internos y familiares de las víctimas, ya que en algunos casos son los propios familiares los que cometen ese delito.

La decadencia de valores en el núcleo familiar y la pornografía desmedida mediante los dispositivos electrónicos, han influenciado en el comportamiento del sujeto activo del delito, ya que los principios delincuenciales se deben a la mala formación del ser humano en la etapa de adolescencia, pues éstos no obtuvieron la educación adecuada y ni una formación psicológica sana en cuanto a la sexualidad.

Algunos de los sujetos activos en delitos sexuales, se deben a traumas sufridos en la niñez, es decir lo que les hicieron a ellos, lo reflejan mediante un comportamiento equivocado y victimizan a seres mediante el abuso sexual.

Para llegar a una sentencia condenatoria, los jueces deben estar completamente seguros de la culpabilidad y evitar que los niños sean las carnadas y medios para cobrar ciertas rencillas que existan entre las partes procesales, con el testimonio de las víctimas de abuso sexual en la actualidad se ha llegado a una sentencia condenatoria, sin analizar psicológicamente si se encuentran capaces mentalmente y en qué condiciones dieron su testimonio en la audiencia de juzgado.

En este sentido jurídico, Panta (2005), manifiesta que:

En el desarrollo de un proceso penal, muchas veces la única prueba de cargo resulta ser la manifestación del propio agraviado que se convierte en único testigo, con lo que se convierte a la valoración probatoria en una verdadera encrucijada. Delitos, sobre todo contra la libertad sexual en la modalidad de violación de menor de edad, son los que con más frecuencia presentan estos problemas, pues el juzgador tiene la difícil tarea de desentrañar este testimonio y determinar si constituye prueba válida, de cara a la condena de un imputado. (p. 3).

Considerando de esta forma, que el testimonio de los niños y adolescentes víctimas del delito de abuso sexual, es la única prueba de cargo a favor de la víctima, frente a esto también, es la que se ha constituido como prueba suficiente para condenar al procesado, ya que particularmente en este tipo de delito no se puede sustentar con otros medios de prueba que asegure con exactitud la materialidad y responsabilidad de la infracción, razón de que una característica principal en cuanto a la perpetración del delito es la clandestinidad de las circunstancias de los hechos, que en muchos casos no dejan huellas ni testigos que afirmen la verdad del testimonio de la víctima. 
Además en muchas ocasiones, estos actos, son las que también han llevado al error a los juzgadores y operadores de justicia, donde se han procesado y condenado a prisión a muchos inocentes, a su vez, se han absuelto de culpabilidad a muchos responsables, dejando en la impunidad el delito.

Por esto, se ha visto en la necesidad de reestructurar el sistema de justicia y la legislación penal, donde garantice los derechos tanto de la víctima como del procesado, para evitar la impunidad del delito, o una condena equivocada. Por ello, es necesario que tanto los juzgadores, como los auxiliares de la administración de justicia, se encuentren dotados de conocimientos científicos más allá de la experiencia, desde que se realiza el diagnóstico correspondiente a la víctima hasta el momento de valorar las pruebas pertinentes, que en este caso vendría a ser el testimonio de los menores.

Por tal motivo, la investigación se centra en describir a través de un análisis crítico y jurídico el efecto jurídico que provoca el testimonio de los niños y adolescentes víctimas del delito de abuso sexual, en las sentencias emitidas en el tribunal de Garantías Penales con sede en el cantón Riobamba, Ecuador. Esta investigación es de novedad científica pues servirá como aporte teórico, metodológico y científico de apoyo a docentes y estudiantes en general.

\section{El delito de abuso sexual}

El delito de abuso sexual, al ser una nueva figura que reemplazo al delito de atentado al pudor, es considerado como todo acto sexual sin que exista copula carnal sobre la víctima, siendo los más comunes dentro del núcleo familiar o entre personas cercanas y/o conocidas.

Por tanto, en este delito al no ser necesario la penetración o acceso carnal para que sea considerado como infracción penal, el delito de abuso sexual consiste en todos aquellos actos sexuales que atentan contra la integridad sexual y el pudor de la víctima, ejecutados sobre otra persona de uno u otro sexo, principalmente niños, niñas y adolescentes mediante violencia efectiva o presunta, con exclusión del coito.

Por otro lado, la Dra. Calderón, en un artículo publicado en la Revista Judicial define el abuso sexual como:

La participación del menor en actividades sexuales para las cuales no está preparado y por lo tanto no puede dar consentimiento. El abuso sexual no necesariamente implica relación sexual o la fuerza física, en muchos casos los niños y las niñas pueden ser sobornados(as), presionados(as) o amenazados(as) verbalmente para que realicen actos sexuales. (Calderón, 2005).

Respecto a las diferentes formas de llevar a cabo la consumación de un delito, refiriéndose específicamente al abuso sexual Orjuela y Rodríguez (2012), consideran que: 
El abuso sexual infantil puede incluir contacto sexual, aunque también actividades sin contacto directo como el exhibicionismo, la exposición de niños o niñas a material pornográfico, el grooming o la utilización o manipulación de niños o niñas para la producción de material visual de contenido sexual. (p. 24).

Desde este punto de vista, se sostiene que el abuso sexual puede manifestarse de la siguiente manera:

Al existir contacto físico. Es el acercamiento o contacto físico entre el cuerpo del sujeto activo del delito y el sujeto pasivo o víctima, donde el victimario generalmente adulto, utiliza a niñas. niños y adolescente menores, para estimularse sexualmente el mismo, al menor o a otra persona.

Sin contacto físico. Otra manera es la verbal, conformado por propuestas indecentes y verbales explícitas. A este tipo de abuso sexual corresponde la acción de obligar a la víctima a presenciar u observar determinados actos de naturaleza sexual.

\section{Signos de posible abuso sexual}

Cuando un niño o adolescente, sufre abuso sexual las secuelas son irreparables, tal como manifiesta Orjuela y Rodríguez (2012), siendo los signos:

Miedos; fobias; síntomas depresivos; ansiedad. baja autoestima; sentimiento de culpa; estigmatización; trastorno por estrés postraumático; ideación y conducta suicida; autolesiones; conductas hiperactivas; funcionamiento cognitivo general; trastorno por déficit de atención con hiperactividad; menor cantidad de amigos; elevado aislamiento social; problemas de sueño (pesadillas); pérdida del control de esfínteres (enuresis y encopresis); trastornos de la conducta alimentaria; quejas somáticas; conducta sexualizada: masturbación compulsiva; imitación de actos sexuales; uso de vocabulario sexual inapropiado; curiosidad sexual excesiva; conductas exhibicionistas; conformidad compulsiva; conducta disruptiva y disocial; hostilidad; agresividad; ira y rabia; trastorno oposicionista desafiante. (pp. 16-18).

Además, los delitos de agresiones sexuales no únicamente causan perturbaciones físicas y psicológicas en las víctimas, sino también los que sufren un grado de afectación son los familiares, ya que muchas veces las víctimas por el estado depresivo en que se encuentran incluso han llegado al extremo de quitarse la vida.

\section{El abuso sexual en el núcleo familiar}

El abuso sexual en el núcleo familiar es el más común, y la mayoría de estos abusos sexuales familiares quedan en la total impunidad, razón de que por la intimidación del sujeto activo del delito hacia su víctima, que en este caso sería un miembro del núcleo familiar nunca se llega a la denuncian y menos al inicio del proceso penal. 
En este sentido Aguilar (2009), considera que:

Cualquier acción de un familiar que involucre a un menor en actividades de índole sexual. Dentro de este grupo diferenciamos las acciones que incluyen contacto físico de aquellas otras que carecen de este elemento. Dentro de esta tipología se citan el incesto (familiares cercanos), estimulación sexual (tocamientos, masturbación), vejaciones, violación, exhibicionismo, explotación sexual (pornografía infantil, prostitución), etc. (p. 214).

\section{El sujeto activo del delito}

Sujeto activo es la persona física que comete el delito, llamado también; delincuente, agente o criminal, será siempre una persona física, independientemente del sexo, edad y en el caso de minoría de edad da lugar a la inimputabilidad. Por consiguiente cada tipo (descripción legal de un delito) señala las calidades o caracteres especiales que se requieren para ser sujeto activo.

\section{La obtención del testimonio del menor}

Siendo, el testimonio de los menores víctimas, un elemento con el que se inicia un proceso penal, se indica que esta diligencia debe ser receptado con atención y cuidado frente a lo que se está relatando, y cuyo informe pericial del profesional sea sin ningún tipo de prejuicios, apegados a la realidad de los dicho lo más exacto posible, por ello, Juárez (2004), manifiesta que "es muy importante advertir que la función del psicólogo en el ámbito forense no es llegar a conclusiones respecto a la sentencia, sino facilitar los conocimientos especializados para que sea el juez o el jurado quien las elabore”. (pp. 32-33).

Por ello, para efecto de la obtención del testimonio se considera dos formas que generalmente se aplican:

Recuperación narrativa. Es en el que simplemente se pide al testigo que cuente qué sucedió. En términos de tareas de memoria se pide que realice una tarea de recuerdo libre: que sin limitación alguna y sin interrupciones cuente todo lo que recuerde, de la forma que prefiera, en relación a este enunciado Pavón (2006) señala que:

Se pide al sujeto que narre los hechos de los que ha sido testigo y los relate ordenadamente. Por razones de inestabilidad psíquica y otros factores, el testigo recorta lo dicho, pero olvida detalles que el interrogador debe precisar en preguntas una vez terminada la exposición. (p.168).

Recuperación interrogativa. consiste en realizar una serie de preguntas a los testigos que previamente han sido elaboradas formando el guion del interrogatorio, que puede ser implícito o explícito. En términos de tareas de memoria se pide al testigo que realice una tarea de recuerdo 
dirigido, recuerdo con indicios o reconocimiento, de igual forma Pavón (2006), señala que "en la forma interrogativa, se solicita al sujeto la descripción de un daño concreto ¿Cómo era el arma? esta aparta más detalles, pero existe la posibilidad de cometer más errores". (p. 168).

\section{Análisis del contenido del testimonio de la victima}

El análisis se basa en los relatos de un suceso que ha sido percibido por la víctima o testigo, donde se pretende diferenciar los relatos de un suceso que no ha sido percibido, o ha sido generado como por ejemplo por fantasías, sueños, pensamientos, etc. es decir, se trata de establecer si el testimonio tiene un origen real o un suceso irreal. (Juárez, 2004, p.49).

Por otro lado, es necesario indicar que el análisis de credibilidad se ocupa de evaluar el grado de realidad de la declaración, pero un resultado negativo no indica necesariamente falsedad en la misma, esto es, no es un análisis de detección de mentiras. No se trata, por tanto, de establecer la verdad o mentira de la declaración, sino únicamente de analizar si cumple con algunos criterios, establecidos por la investigación psicológica, cuya presencia indica una probabilidad alta de corresponder a un hecho real.

\section{Verdad o mentira en el testimonio de la víctima de abuso sexual}

Par que sea real el testimonio de la víctima o testigo, según Cafferata (1998), sostiene que:

El conocimiento que pueda tener el testigo sobre los hechos investigados deberá haberlo adquirido antes de ser llamado y por percepción sensorial: expresará lo que vio, oyó, olió, gustó o tocó. En cambio, si previo encargo judicial refiere conclusiones a las cuales ha llegado por sus conocimientos científicos, técnicos o artísticos, no se tratará propiamente de un testigo, sino más bien de un perito. (p. 96).

Desde esta perspectiva, para que el testimonio de la víctima sea creíble y considerada como tal, es necesario tratar de verificar con otros medios de prueba que evidencien en realidad si la víctima estaba involucrada pasivamente en la ejecución del hecho delictual, ya que el testimonio a decir no debe ser premeditado u objeto de sugestión de una tercera persona, donde dicho testimonio debe contener la realidad que pudo experimentar o sentir la víctima de agresión sexual.

Por otro lado, la creencia en la incapacidad del niño para inventar una compleja relación sexual y la aparición de conductas asociadas, serían los rasgos más importantes. Sin embargo, a estos rasgos se les puede hacer una importante crítica, ya que ciertas evidencias son ambiguas o tiene un cierto sesgo, mientras que por otra parte, tanto el denunciado se encuentre implicada en casos de disputa por custodia o visitas, como la persona que denuncia presente problemas mentales o de personalidad, no tiene por qué ir asociado a la imposibilidad de abuso. 
Así que, los delitos sexuales contra menores son un tipo de delito que, por sus características, implica una difícil valoración. Las técnicas utilizadas tanto desde el punto de vista lego (jurados) como desde el punto de vista experto consistentes en analizar a imputado y víctima (conductas, rasgos de personalidad) podrían tener ciertos problemas o sesgos que llevarían a conclusiones erróneas. Por otro lado, desde un punto de vista legal no pueden hacerse valoraciones de la credibilidad del testigo, sólo de su testimonio, y en todo caso, no puede hablarse de la exactitud o realidad (veracidad) de un relato, competencia que le corresponde al estamento encargado de juzgar un delito, jueces y tribunales de justicia.

\section{Medios de prueba y el testimonio de la víctima de abuso sexual}

\section{Procedimiento}

En la fase pre procesal se recaba elementos de convicción.

En la etapa de instrucción fiscal se vuelve a recabar los mismos elementos de convicción de la fase pre procesal o investigación previa.

En la audiencia preparatoria de juicio, llamada también etapa intermedia se analiza los elementos recabados en la instrucción fiscal y de presumirse la culpabilidad se llama a juicio al procesado o en su defecto se dicta el auto de sobreseimiento.

En etapa de juicio, la audiencia de juzgamiento se judicializa los elementos de convicción con el testimonio de los peritos que elaboraron dichos informes.

En relación a esto, el 612 inciso 3 del Código Orgánico Integral Penal determina:

Una vez iniciada la audiencia, si al momento de intervenir algún perito o testigo no se encuentra presente o no puede intervenir a través de algún medio telemático, se continuará con los peritos o testigos presentes y demás medios de prueba. (p.100).

Así que, corresponde a las partes procesales poseer todos los medís de prueba para el momento de la audiencia, por cuanto a falta de algún testigo o perito no implica que la audiencia pueda suspenderse, sino tal como determina el COIP la audiencia continuara con los peritos o testigos que puedan estar presentes.

Tipos de elementos de convicción para determinar la materialidad de la infracción en el delito de abuso sexual

Generalmente los elementos de convicción que se recaban frente a este tipo de delito son los siguientes: 
- Reconocimiento del lugar de los hechos, con su respectivo informe elaborado por un perito calificado.

- Reconocimiento de la evidencia, con su respectivo informe elaborado por un perito calificado.

- Reconocimiento psicológico al menor afectado, con su respectivo informe elaborad por un perito calificado.

- La elaboración del parte policial, cuya judicialización será en la audiencia de juzgamiento con su testimonio.

En este sentido, se puede verificar que el abuso sexual por caracterizarse como un delito que se comete de manera oculta y secreta que muchas veces no dejan rasgos visibles, imposibilita que en la investigación se pueda recabar otros medios de prueba, considerándose por tanto que en este tipo de delito las diligencias de actividad probatoria tienen un grado de limitación.

\section{Reglas para la recepción de testimonio de la víctima}

Por principio general, en todo proceso judicial la comparecencia de un menor a juicio $u$ otros actos jurídicos debe estar debidamente representado, razón de que frente a la Ley son considerados incapaces; por consiguiente para poder actuar en el mundo jurídico deben hacerlo por interpuesta persona, es decir mediante representante, donde esta representación puede ser correspondido a los progenitores o a los curadores según sea el caso.

Por ello, el Código Orgánico Integral Penal COIP en el artículo 502, número 5 expresamente determina que, "las niñas, niños y adolescentes declararán sin juramento, pero con la presencia de sus representantes o un curador que será nombrado y posesionado en la misma audiencia de juicio". (p.81).

Además, una de las características del testimonio de los niños y adolescentes que se encuentra determinada en el COIP, es que tal declaración de los menores sin juramento. En tal virtud, y en atención a lo dispuesto en el artículo 510 del COIP, los jueces se rigen a las siguientes reglas en cuanto a la recepción del testimonio de la víctima:

1.La víctima previa justificación podrá solicitar a la o al juzgador se le permita rendir su testimonio evitando la confrontación visual con la persona procesada, a través de video conferencia, cámara de Gesell u otros medios apropiados para el efecto, sin que ello impida el derecho a la defensa y en especial, a contrainterrogar, en el cual la o el juzgador deberá cerciorarse de la identidad de la persona que rinde el testimonio a través de este medio.

2.La o el juzgador dispondrá, a pedido de la o el fiscal, de la o el defensor público o privado o de la víctima, medidas especiales orientadas a facilitar el testimonio de la víctima y en particular de niñas, niños, adolescentes, víctimas de delito contra la integridad sexual. 
3.La o el juzgador, adoptará las medidas necesarias para evitar cualquier tipo de hostigamiento o intimidación a la víctima, especialmente en casos de delitos contra la integridad sexual.

4.Siempre que la víctima lo solicite o cuando la o el juzgador lo estime conveniente y la víctima lo acepte, el testimonio será receptado con el acompañamiento de personal capacitado en atención a víctimas en crisis, tales como psicólogos, trabajadores sociales, psiquiatras o terapeutas, entre otros. Esta norma se aplicará especialmente en los casos en que la víctima sea niña, niño, adolescente. (p.83).

\section{El examen psicológico efectuado a los niños o adolescentes, víctimas del delito de abuso sexual en la etapa de instrucción fiscal}

Con el examen psicológico, se trata de alguna manera de determinar el grado de afectación emocional a la víctima, considerando a la psicología como una ciencia que se enfoca al estudio de la personalidad del ser humano.

Respecto a esta moción, la función del perito psicólogo no es solamente dar un informe en favor de la víctima, razón de que pueden presentarse casos en que no haya ninguna afectación cuando se trate de una falsa imputación, por cuanto, luego del testimonio de la víctima y tomando en cuenta el examen psicológico es donde se da inicio el proceso penal.

En este sentido, una vez que se presuma del supuesto abuso sexual, el fiscal ordenara de oficio o a petición de parte solicitara la experticia del reconocimiento psicológico al menor que presuntamente haya sido víctima de abuso sexual.

Luego de que el perito haya concluido con la elaboración de su informe determinara si hubo o no dicha agresión sexual, donde el fiscal debería pedir un nuevo reconocimiento psicológico con otro perito para corroborar si coinciden ambos informes.

\section{Causas que pueden ocasionar la falsedad de testimonio de la víctima de abuso sexual}

Pavón (2006), haciendo mención a las respuestas falsas en el testimonio dicen "toda respuesta es una narración mixta en la que ingresan no solo las vivencias espontaneas del interrogado, sino también las representaciones y tendencias afectivas evocadas a las preguntas a la que se responde". (p.168).

De tal manera, que puede acontecer la falsedad en el testimonio de la víctima por las siguientes razones:

- Que la pregunta, no sea concordante a testificar, es decir que el sentido de la pregunta sea distinto a la realidad de los hechos. 
- Que la pregunta verse sobre hechos o asuntos desconocidos, donde el sujeto trata de dar su respuesta al azar o basada en ideas que suponen estar en lo cierto; se da cuando una persona desconoce algún significado al momento de testificar.

- Que la pregunta a contestar cause temor que pueden ser reemplazados con otros datos, principalmente cuando se trate de hacer la declaración en contra del abusador que pueda haber alguna amenaza por parte de sujeto activo.

- La edad del que testifica, es por esto que se había señalado que no es lo mismo la capacidad de entender y conocer entre un niño, adolescente y un adulto.

Al respecto, se dice que los niños por el hecho mismo de la falta de desarrollo emocional y personal, tiene un grado de conocimiento muy relativo y de carácter superficial, donde todo lo que se presenta en el mundo exterior captan de una manera espontánea, y la manera de cómo interpreta las cosas se realiza de acuerdo a su grado de conocimiento y percepción, lo que convierte que el testimonio del menor víctima se convierta ambigua al momento de determinar la culpabilidad del presunto autor del delito de abuso sexual.

\section{MÉTODO}

La metodología de la investigación fue de tipo descriptiva y causal, porque permitió explicar las causas y consecuencias que produce el testimonio de los niños y adolescentes víctimas del delito de abuso sexual y su efecto jurídico en las sentencias emitidas en el tribunal de Garantías Penales con sede en el cantón Riobamba, Ecuador.

El diseño de la investigación se basó en el no experimental, ya que no se trabajó con grupos de control, tampoco se manipuló intencionalmente ninguna variable, es decir se estudió el problema tal como se dio en su contexto.

El método usado fue inductivo, a través de la utilización de este método se logró estudiar el problema desde lo particular para llegar a lo general donde se realizó un análisis sobre el testimonio de los niños y adolescentes víctimas del delito de abuso sexual y su efecto jurídico en las sentencias emitidas en el tribunal de Garantías Penales con sede en el cantón Riobamba, Ecuador.

Por otro lado, las técnicas utilizadas para la recolección de datos en la investigación fueron el fichaje y la encuesta, y los instrumentos, fichaje bibliográfico, donde se recopilo información sobre las sentencias emitidas por los jueces de los Tribunales de Garantías Penales con sede en el cantón Riobamba, así como conceptos, teorías y artículos de la bibliografía que se utilizaron en la investigación para fundamentar la teoría. Y un cuestionario, el cual, fue aplicado a los jueces, abogados, fiscales, con preguntas abiertas, cerradas, opción múltiple, mismas que estarán enfocadas a las variables de estudio. 
La población y muestra usada en la investigación, estuvo conformada por (6) Jueces del Tribunal de Garantías Penales con sede en el cantón de Riobamba, (4) Fiscales y (4) Abogados en libre ejercicio de la profesión.

RESULTADOS

De acuerdo al método inductivo aplicado y conforme a los resultados obtenidos posterior a la aplicación de las encuestas realizadas a 6 jueces del tribunal Penal de la Unidad Judicial con sede en el cantón Riobamba, 4 fiscales y 4 abogados en libre ejercicio. Se pudo analizar que:

La totalidad de los entrevistados manifestó que conoce acerca del delito de abuso sexual; así como también todos los entrevistados manifestaron que el testimonio de las víctimas de abuso sexual causa un efecto jurídico al momento de dictar sentencia; además se comprobó que el total de la población encuestada indicó que no se aplicó atenuantes en los delitos sexuales; y afirmaron que se aplica agravantes en los delitos sexuales.

A su vez, el total de la población encuestada señaló que sí se utilizan la sana critica al momento de emitir una sentencia; y afirmaron que tiene eficacia jurídica el testimonio de las víctimas en los delitos sexuales; por lo que, con el testimonio de las víctimas en los delitos sexuales se puede dar una sentencia condenatoria; además, se recalcó que los niños son influenciados por sus familiares para mentir de un supuesto delito de abuso sexual.

Por último, todas las personas encuestadas indicaron que no tiene eficacia el examen psicológico practicado por un perito calificado; y afirman que se aplica la duda a favor del reo en los casos de abuso sexual.

En base a la información y criterios obtenidos en la investigación se logró determinar que efectivamente el testimonio de los niños y adolescentes víctimas del delito de abuso sexual, causa efecto en las sentencias emitidas por la unidad Judicial penal con sede en el cantón Riobamba.

CONCLUSIONES

Partiendo de los resultados obtenidos en la investigación se logró concluir que, en los delitos de abuso sexual, son más susceptibles los niños y adolescentes y el mayor de los casos los agresores son miembros del núcleo familiar y conocidos. Se evidencio claramente que las sentencias de abuso sexual se basan en el testimonio de la víctima, para emitir su resultado, con el argumento que los niños no mienten.

Además, el examen psicológico practicado a las víctimas de abuso sexual no refleja un resultado veraz para determinar si el niño está mintiendo. Y a su vez, no hay suficientes elementos de convicción practicados en la etapa de instrucción fiscal para determinar la culpabilidad del procesado en los delitos de abuso sexual.

En tal sentido, se puede decir que se pudo cumplir con el objetivo principal de la investigación. 


\section{REFERENCIAS}

Aguilar, M. (2009) Revista Abuso Sexual en la Infancia-Entidad Editora Universidad de Murcia

Cafferata, J. (1998). La Prueba en el Proceso Penal. Editorial De Palma. 3ra Edición. Buenos Aires

Calderón, S. (2005). Abuso sexual de menores. Impactos psicológicos y físicos. Recuperado en: [https://www.derechoecuador.com/abusosexual-de-menores]

Código Orgánico Integral Penal-SuplementoRegistro Oficial $\mathrm{N}^{\circ} 180$ lunes 10 de febrero del 2014

Juárez, J. (2004). La credibilidad del testimonio infantil ante supuestos abusos sexuales: Indicadores psicosociales. Tesis Doctoral,
Universitat de Girona. Recuperado en: [http:// www.buentrato.cl/pdf/est_inv/maltra/mi juarez.pdf]

Orjuela, L.; y Rodríguez, V. (2012). Violencia Sexual Contra los Niños y Niñas, Abuso y Explotación Sexual Infantil-Editorial Save The ChildremEspaña

Panta, D.; y Somocurcio, V. (2005). La Declaración de la Víctima en los delitos Sexuales iInflexión en la Exigencia de una Suficiente Actividad Probatoria? Análisis del Acuerdo Plenario $N^{\circ} 2$ 2005/CJ-116-Lima Perú

Pavón, F. (2006). Psicología Jurídica y Psiquiatría Forense. Editorial Facso. Quito Ecuador 